\title{
Adverse Fetal and Neonatal Outcomes following in-utero exposure to Oxcarbazepine: A Systematic Review and Meta-Analysis.
}

\author{
Farwa Athar ${ }^{1}$, Muhammad Ehsan ${ }^{1}$, Minaam Farooq ${ }^{1}$, Kevin Lo ${ }^{2}$, Huzaifa Cheema ${ }^{1}$, \\ Shahzaib Ahmad ${ }^{1}$, Aiman Naveed ${ }^{1}$, and Muhammad Umer ${ }^{1}$ \\ ${ }^{1}$ King Edward Medical University \\ ${ }^{2}$ Einstein Medical Center Philadelphia School of Radiologic Technology
}

February 11, 2022

\begin{abstract}
Aim: This systematic review aims to assess the safety profile of oxcarbazepine during pregnancy. Methods: Observational studies that included women who took oxcarbazepine anytime during pregnancy were included in our systematic review. The review did not include non-English articles, reviews, meta-analyses, case reports, and animal studies. Different online sources such as MEDLINE, Cochrane library, Virtual Health library etc. were searched for published and unpublished literature. Assessment of risk of bias of observational studies was done using the Newcastle-Ottawa Scale. The meta-analyses were performed using a random-effect model. GRADE was used for the evaluation of the quality of evidence for the primary outcomes. Results: We included 19 cohort studies with a total number of 5,071,137 patients, of which 2,450 were exposed to oxcarbazepine either as monotherapy or polytherapy. The summary odds ratio (OR) was 1.69 (95\% CI, 0.95-2.98) for congenital malformations following in-utero exposure to oxcarbazepine as compared to the control group of unexposed patients [seven studies ( $\mathrm{n}=625)$ ], and was 1.19 (95\% CI, 0.67-2.12) when compared to those following lamotrigine (LTG) exposure during pregnancy [3 studies $(\mathrm{n}=591)]$. In total, three studies $(\mathrm{n}=770)$ reported the association between in-utero oxcarbazepine exposure and fetal/perinatal deaths. The meta-analysis yielded a summary OR of 3.11 (95\% CI, 0.57-16.97). Significance: Our systematic review will help healthcare providers and guideline developers regarding the treatment of epilepsy and other neurological disorders during pregnancy. More cohort studies with a higher sample size concerning oxcarbazepine use in pregnant patients are required to truly assess the in-utero safety profile of the drug.
\end{abstract}

\section{Hosted file}

Manuscript.docx available at https://authorea.com/users/460027/articles/556116-adversefetal-and-neonatal-outcomes-following-in-utero-exposure-to-oxcarbazepine-a-systematicreview-and-meta-analysis 


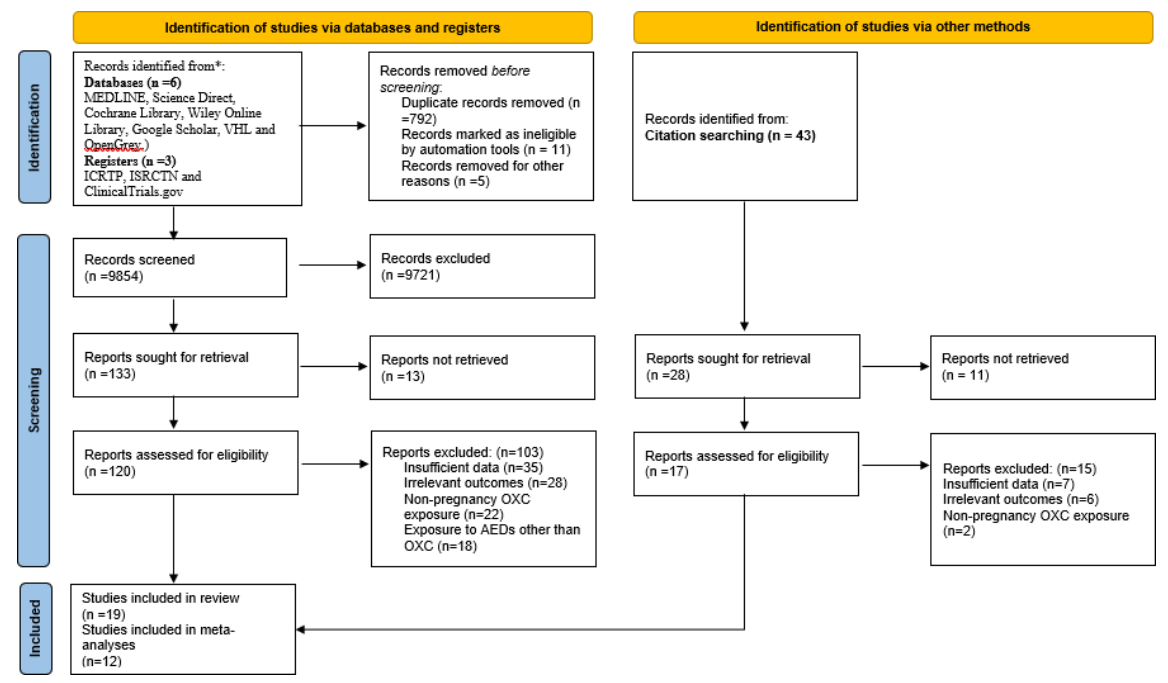

Quality Assessment (NOS)
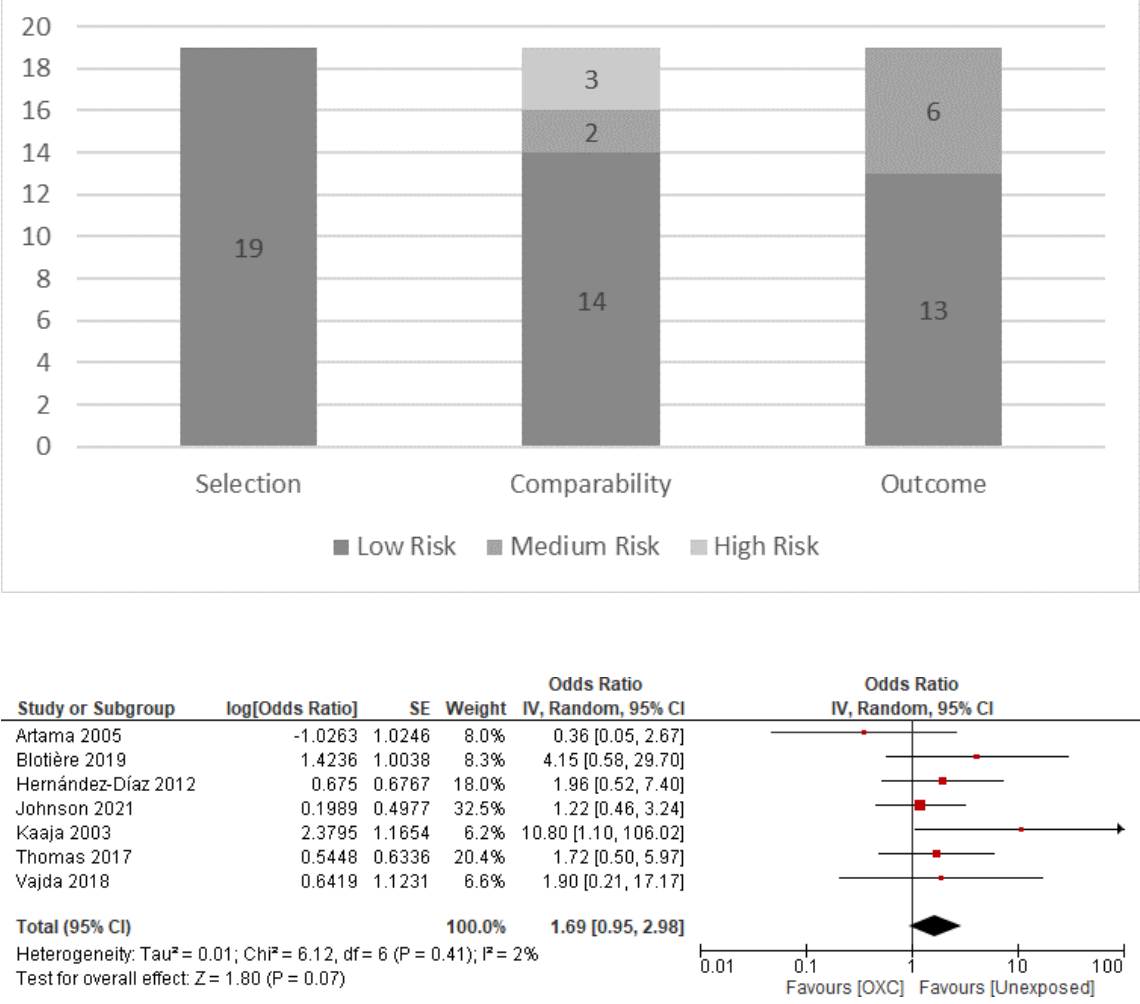

Odds Ratio

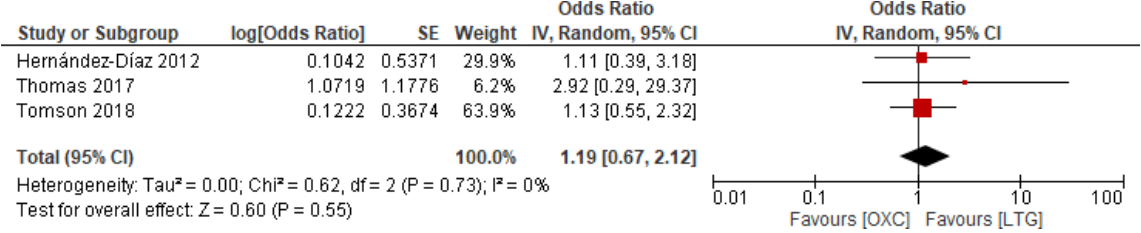


Odds Ratio Odds Ratio

\begin{tabular}{|c|c|c|c|c|c|c|c|c|}
\hline Study or Subgroup & log[Odds Ratio] & SE & Weight & IV, Random, $95 \% \mathrm{Cl}$ & & IV, Rando & m, $95 \% \mathrm{Cl}$ & \\
\hline Artama 2013 & 0.9361 & 0.3846 & $76.6 \%$ & $2.55[1.20,5.42]$ & & & & \\
\hline Trivedi 2018 & 2.0189 & 0.8098 & $17.8 \%$ & $7.53[1.54,36.82]$ & & & & \\
\hline Vajda 2018 & 2.2395 & 1.4358 & $5.7 \%$ & $9.39[0.56,156.59]$ & & & & \\
\hline Total $(95 \% \mathrm{Cl})$ & & & $100.0 \%$ & $3.33[1.70,6.51]$ & & & & \\
\hline $\begin{array}{l}\text { Heterogeneity: Tau } \\
\text { Test for overall effec }\end{array}$ & $\begin{array}{l}0.01 ; \mathrm{Chi}^{2}=2.02 \\
Z=3.51(\mathrm{P}=0.00\end{array}$ & $\begin{array}{l}d f=2(P \\
04)\end{array}$ & $=0.36) ; I^{\prime}$ & $=1 \%$ & 0.01 & $\begin{array}{c}0.1 \\
\text { Favours [OXC] }\end{array}$ & \begin{tabular}{|cc}
10 & 10 \\
Favours [control]
\end{tabular} & 100 \\
\hline
\end{tabular}

